\title{
IMPUESTO A LA RENTA PERUANO Y LAS RESTRICCIONES PARA DEDUCIR GASTOS CAUSALES
}

\section{PERUVIAN INCOME TAX AND RESTRICTIONS TO DEDUCT CAUSAL EXPENSES}

Catya Vásquez Tarazona

Doctora en Contabilidad y Finanzas - Docente de la Facultad de Ciencias Contables de la Universidad Nacional Mayor de San Marcos, Lima, Perú - Email: cvasquezt@unmsm.edu.pe (Autor Corresponsal)

[Recibido: 14/08/2016 Aceptado: 18/11/2016]

\section{RESUMEN}

En el actual Texto Único Ordenado de la Ley del Impuesto a la Renta aprobado por el D.S. N¹79-2004-EF y normas modificatorias, se han establecido restricciones en la deducción de los costos o gastos que afectan la determinación de la renta neta, desconociendo su realidad económica. El hecho que en la Ley del Impuesto a la Renta existan restricciones en la deducción de algunos gastos condicionándolos al pago previo, generan un mayor gasto corriente por Impuesto a la Renta en las empresas, lo podría trasgredir el principio de capacidad contributiva. Por ello, en el presente artículo se presenta el análisis de los gastos sujetos a restricción descritos en los incisos I) y v) del artículo $37^{\circ}$ la mencionada base legal, los cuales se encuentran condicionados al pago previo para que puedan ser deducibles en el ejercicio gravable. Mediante la aplicación de los diferentes instrumentos de recolección de datos y técnicas de obtención de información documental se observó que la Ley del Impuesto a la Renta no permite imputar correctamente los gastos de la tercera categoría, puesto que restringe indebidamente la imputación de algunos gastos.

\section{PALABRAS CLAVE}

Impuesto, renta, gastos deducibles, restricción.

\begin{abstract}
In the current Consolidated Text of the Law on Income Tax approved by S.D. No. 179-2004-EF and amendments, restrictions have been placed in deduction of costs or expenses that affect the determination of net income, ignoring economic reality. The fact is that in the Law on Income Tax restrictions exist on the deduction of certain expenses conditioning them to advance payment. This generates a higher current expense on income tax in business, what could transgress the principle of contributory capacity. Therefore, we present in this article, the costs analysis subject to restriction described in subsections I) and v) from the Article $37^{\circ}$ of the mentioned legal basis, which are conditioned to the advanced payment so that they can be deductible in the fiscal year. By applying different collection instruments and data collection techniques of documentary information, it was noted that the Law on Income Tax does not allow proper allocation of the third category costs, since it inadequately restricts the allocation of some expenses.
\end{abstract}

\section{KEYWORDS}

Tax, rent, deductible expenses, restriction.

Como Citar: Vásquez, C. (2017). Impuesto a la renta peruano y las restricciones para deducir gastos causales. Quipukamayoc, 25(47), 65 - 74. doi: http://dx.doi.org/10.15381/quipu.v25i47.13804 


\section{INTRODUCCIÓN}

Para todo Estado es importante contar con los ingresos suficientes a fin de poder atender y hacer frente, entre otros, al sostenimiento de su actividad pública.

Los tributos representan una de las principales fuentes de ingresos de todo Estado y el Impuesto a la Renta en el país, constituye uno de los principales tributos, no sólo por su importancia en la recaudación, sino porque en estricto, grava de manera directa las ganancias de los contribuyentes, y por tanto, pretende afectar su verdadera capacidad contributiva.

Por ello, la adecuada determinación de las rentas empresariales, es fundamental, ya que, lo que se busca es que los empresarios tributen acorde a la realidad económica, y por ende se pueda aplicar la tributación con la adecuada justicia distributiva.

En ese sentido, la investigación se realizó con el propósito de establecer si las medidas restrictivas para la imputación y deducción de los gastos o costos condicionándolos al pago previo, afectan la determinación de las rentas netas empresariales, originando ello una potencial afectación a su capacidad contributiva, lo que podría ocasionar un perjuicio económico en las empresas.

Con carácter general, las rentas empresariales se deben imputar en el ejercicio gravable en que se devenguen, y las mismas normas establecidas son de aplicación para la imputación de los gastos; por lo tanto, los gastos serán deducibles, en la medida que cumplan con el principio del devengado.

Asimismo, la Administración Tributaria en el Oficio No 015-2000-K0000 de fecha 2000/02/07, en respuesta a una consulta formulada por la Asociación de Exportadores - ADEX, indicó que en la categoría, los gastos necesarios para producir y mantener la fuente, en tanto la deducción no esté expresamente prohibida, según lo establece el artículo $37^{\circ}$ del TUO de la Ley del Impuesto a la Renta. Pero además del requisito de la relación causal entre el gasto y la fuente productora de renta, y de la no existencia de una prohibición legal para su deducción se debe tener en cuenta los límites o reglas que por cada concepto hubiera dispuesto el referido TUO, cuyo análisis dependerá de cada caso en concreto (Sunat, 2000).

Como se ha señalado anteriormente, el hecho que en el TUO de la LIR existan restricciones en la deducción de los gastos condicionándolos al pago previo, generan una mayor imposición en el Impuesto a la Renta corriente de las empresas, vulnerando de alguna forma el principio de capacidad contributiva, alejando la determinación de la Renta Neta de la realidad.

Para ello, el presente trabajo de investigación se enfocará en el análisis respecto de los gastos sujetos a límite descritos en los incisos l) y v) del artículo $37^{\circ}$ la Ley del Impuesto a la Renta Decreto Supremo N ${ }^{\circ} 179-2004-E F$ y normas modificatorias.

Mediante la Ley $\mathrm{N}^{\circ} 27356$, con vigencia a partir del año 2001, y que modificó el Texto Único Ordenado de la Ley del Impuesto a la Renta, aprobado por Decreto Supremo No 054-99-EF, publicado en el 2000, se incorporaron diversas medidas antielusivas en la Ley del Impuesto a la Renta con la finalidad de garantizar la recaudación; siendo una de ellas, la restricción a deducir los gastos o cos- tos para la determinación de la renta neta empresarial del ejercicio gravable, señalado en el inciso V, del artículo $37^{\circ}$, de la Ley del Impuesto a la Renta y que fuera incorporado por el Artículo $6^{\circ}$ de la Renta neta de tercera categoría de la Ley $N^{\circ} 27356$, señala lo siguiente: Los gastos o costos que constituyan para su perceptor rentas de segunda, cuarta o quinta categoría podrán deducirse en el ejercicio gravable a que correspondan cuando hayan sido pagados dentro del plazo establecido por el Reglamento para la presentación de la declaración jurada correspondiente a dicho ejercicio.

Asimismo, en el Capítulo VI de la Renta Neta, el inciso l del artículo $37^{\circ}$ de la Ley del Impuesto a la Renta y aprobada por el D.S. N¹79-2004EF y normas modificatorias, señala lo siguiente: 1) Los aguinaldos, bonificaciones, gratificaciones y retribuciones que se acuerden al personal, incluyendo todos los pagos que por cualquier concepto se hagan a favor de los servidores en virtud del vínculo laboral existente y con motivo del cese. Estas retribuciones podrán deducirse en el ejercicio comercial a que correspondan cuando hayan sido pagadas dentro del plazo establecido por el Reglamento para la presentación de la declaración jurada correspondiente a dicho ejercicio (Sunat, 2004).

Los incisos mencionados en el párrafo anterior constituyen medidas antielusivas adoptadas por el legislador, mediante la cuales se restringe la deducción de los gastos condicionándolas al pago previo, lo que traen como consecuencia la problemática de no imputar los gastos de acuerdo al principio del devengado, establecido en el Capítulo VIII del Ejercicio Gravable, en el artículo $57^{\circ}$ del TUO de la LIR y aprobada por D.S. $\mathrm{N}^{\circ}$ 179-2004EF y normas modificatorias, señala: 
A los efectos de esta Ley el ejercicio gravable comienza el 1 de enero de cada año y finaliza el 31 de diciembre, debiendo coincidir en todos los casos el ejercicio comercial con el ejercicio gravable, sin excepción.

Las rentas se imputarán al ejercicio gravable de acuerdo con las siguientes normas:

a) Las rentas de la tercera categoría se considerarán producidas en el ejercicio comercial en que se devenguen (Sunat, 2004).

Las rentas de las personas jurídicas se considerarán del ejercicio gravable en que cierra su ejercicio comercial. De igual forma, las rentas provenientes de empresas unipersonales serán imputadas por el propietario al ejercicio gravable en el que cierra el ejercicio comercial (Sunat, 2004).

Como se aprecia de la lectura del párrafo anterior el mencionado artículo $57^{\circ}$ del TUO de la LIR, nos indica cómo se debe realizar la imputación de ingresos y gastos para la determinación de las rentas netas empresariales, por ello la restricción de condicionar al pago previo los gastos señalados en los incisos l) y v) del artículo $37^{\circ}$ del TUO de la LIR, originan que los contribuyentes determinen un mayor pago de impuesto al debido.

En ese sentido, en el presente trabajo de investigación se realizó el análisis en los incisos l) y v) del artículo $37^{\circ}$ del TUO de la LIR Decreto Supremo $\mathrm{N}^{\circ}$ 179-2004-EF y normas modificatorias.

En la actualidad no existen investigaciones realizadas sobre la imputación de costos o gastos deducibles condicionados al pago previo. Por tal motivo, en el presente trabajo de investigación, centraré mi atención en aquellos costos o gastos deducibles, cuya imputación y deducibilidad se encuentran condicionadas al pago previo, para la determinación de las rentas netas empresariales.

El presente trabajo de investigación, es importante porque ha permitido demostrar, que el hecho de implementar como medida de prevención de evasión fiscal, el condicionamiento al pago previo, para la imputación y deducibilidad de algunos gastos o costos, en la determinación de las rentas netas empresariales no es una medida de carácter óptimo, en tanto, se transgrede el principio del devengado, generando en los contribuyentes una mayor imposición a la debida.

Los alcances de la investigación fueron los siguientes:

Científico: Al establecer de manera más correcta la deducción de los gastos o costos, que son necesarios para producir la renta neta empresarial, sin condicionarlos al pago previo, se logrará que el principio del devengado - que debe siempre regir como principio fundamental en el derecho tributario - se cumpla de manera más técnica, efectiva y correcta.

Económicos: En tanto, se admita la deducción de los gastos o costos para obtener la renta neta empresarial siempre que estos gastos o costos, sean necesarios para la generación de la renta - se logrará que las empresas puedan tributar de manera más justa, logrando que las empresas tributen e ingresen al fisco los impuestos que en definitiva le correspondan.

Sociales: El lograr corregir la restricción en la deducibilidad de los gastos o costos, que son necesarios para la determinación de la renta neta empresarial; permitirá de manera universal, los contribuyentes determinen de manera más eficiente sus correctas obligaciones tributarias.
La limitacines del estudio fueron de espacio, realizándose la evaluación del impacto de la medida fiscal en todo el territorio peruano en razón de que el impuesto a la renta es un tributo del gobierno central, sin embargo, se hace énfasis en el análisis e investigación de los contribuyentes residentes en Lima Metropolitana. Y de tiempo, periodo que comprendido desde el caso que se aborda desde el año 2001 hasta la fecha (marzo 2017); período de inicio que involucra el año a partir del cual se promulgó la norma restrictiva de la imputación del gasto y periodo final que es la fecha de cierre del presente trabajo de investigación.

El objetivo de la investigación fue la de contribuir con las estrategias de fiscalización, al demostrar que se pueden aplicar medidas adecuadas de control tributario, para la deducibilidad de costos o gastos que cumplan con el principio de causalidad, evitando la indebida restricción de la deducción, como el condicionamiento al pago previo.

Del mismo modo, se demostrará, que la existencia de implementar restricciones en la deducibilidad de algunos gastos o costos, en la determinación de las rentas netas empresariales, condicionándolos indebidamente al pago previo, originan una mayor imposición por parte de las empresas.

Además de lograr demostrar, que debe aplicarse con carácter general, el principio del devengado para la imputación de los gastos en la determinación de las rentas netas empresariales; y que existen otras medidas distintas al condicionamiento del pago previo, para la imputación y reconocimiento del gasto, que logren aminorar la evasión tributaria.

Los resultados de esta investigación, demostraron que la existencia de 
restricciones en la imputación y deducibilidad de los costos o gatos deducibles, para la generación de las rentas netas empresariales, ocasionan una mayor imposición en las empresas, puesto que, el ingreso devengado producido por estos costos o gastos deducibles, se encuentran afectos al Impuesto a la Renta; contraviniendo con el principio de capacidad contributiva.

Asimismo, el principio de devengado, en la determinación de las rentas netas empresariales, en la legislación peruana; no se aplica de manera amplia, dado que, como bien sabemos los costos y gastos cuya deducción se restringe al pago previo, generaron ingresos devengados.

Además, en la actualidad no existen investigaciones que hayan realizado estudios rigurosos sobre las restricciones para la imputación y deducibilidad de los costos o gastos, que se condicionan al pago.

En nuestro país hasta el 31 de diciembre de 2000, la Ley del Impuesto a la Renta, permitía la deducción para la determinación de la renta neta empresarial, sin exigir el pago previo, de los gastos que constituyen para su perceptor rentas de la segunda, cuarta y quinta categoría.

Por otro lado, en la mencionada Ley ya se permitía realizar la deducción de los gastos para la determinación de las rentas empresariales por concepto de aguinaldos, bonificaciones, gratificaciones y retribuciones que se acuerden al personal, incluyendo todos los pagos que por cualquier concepto se hagan a favor de los servidores en virtud del vínculo laboral existente y con motivo del cese, restringiendo la deducción al pago de las referidas rentas.
Con la presencia de los mencionados gastos deducibles, indicados en el primer párrafo del presente numeral se observó que los contribuyentes deducían muchos gastos relacionados a los perceptores de las rentas de segunda, cuarta y quinta categoría, pero que al no realizar el pago al perceptor de la renta, los perceptores de la renta nunca tributaban, sin embargo, los generadores de las rentas empresariales, se beneficiaban con la deducción, produciéndose un uso abusivo por parte de algunos contribuyentes en el tratamiento tributario en la aplicación de la determinación de la renta neta empresarial, a través de la imputación de algunos gastos en el ejercicio en que se prestaban por las personas naturales, los mismos que no eran pagados, conllevando a que las rentas que se originaban en las personas naturales no se imputaban a ellas, en la medida en que estas no eran pagadas.

Por ejemplo: El contribuyente generador de Renta Neta Empresarial (Renta de la tercera categoría), solicitaba un préstamo a una persona natural en el ejercicio gravable 1, cuyos intereses pactados no eran pagados a la referida persona natural, en razón de ello los efectos tributarios eran que los intereses pactados eran plenamente deducibles en la empresa en aplicación del principio del devengado imputando los gastos por intereses desde el ejercicio 1 , mientras que al no ser pagados los intereses, no se materializaba el ingreso en la persona natural no pudiendo imputarse renta alguna en la medida que para este tipo de rentas, la imputación rige bajo el principio del percibido, y al no estar estos intereses pagados no había renta a imputar.

Por lo antes dicho, ello originaba un escudo fiscal en cabeza de la empresa que imputaba el gasto y una renta que no se sometía a imposición en cabeza de la persona natural en la medida en que esta no era pagada; poniéndose de manifiesto un claro uso abusivo de la norma.

De esta manera se originaba un importante perjuicio fiscal ya que no había neutralidad en la imputación de las rentas en la medida de que abusivamente se imputaban los gastos y no se pagaban conllevando una no imputación de la renta, afectando duramente la caja fiscal.

Estos supuestos se daban sustancialmente cuando el prestador del servicio generaba rentas de la segunda, cuarta categoría y quinta categoría, teniendo en cuenta, que estas tres categorías tienen como característica común que los ingresos o rentas generadas se imputan cuando las mismas se perciben.

Por el escenario antes dicho, y con el afán de corregir ésta práctica abusiva utilizada por algunos contribuyentes , el legislador incorporó a partir del ejercicio 2001 a través de la dación de la Ley $\mathrm{N}^{\circ} 27356$ una medida que pretendía evitar el uso abusivo en la imputación de los gastos antes descritos, en razón de ello añadió un elemento restrictivo el cual consistió en aceptar la imputación de los gastos en el ejercicio en que estos se realizaban siempre y cuando estos eran plenamente pagados a la persona natural hasta el vencimiento del plazo de la declaración jurada anual del impuesto a la renta del ejercicio al que corresponda el gasto.

Considerando esta medida correctiva, a manera de ejemplo tenemos: si una empresa recibe un servicio de un profesional independiente (que para la empresa representa gasto o costo) durante el ejercicio gravable 1 y no lo paga en el mismo o hasta el vencimiento de la presentación de la decla- 
ración jurada anual de renta correspondiente a dicho ejercicio gravable; en aplicación estricta y plena del principio del devengado es obligatorio registrar el costo o gasto en ese ejercicio 1, así como realizar el reconocimiento de la obligación generada por el mismo, independientemente a que se haya realizado o no el pago; sin embargo, en aplicación de la norma legal este gasto no es fiscalmente deducible en el referido ejercicio gravable 1.

$\mathrm{Al}$ respecto se debe mencionar que el principio de causalidad, sí está recogido en la norma (artículo $37^{\circ}$ TUO de la LIR), en donde se precisa que todo gasto debe de estar relacionado con la generación del ingreso, es decir, debe de existir una relación entre el gasto que se pretende deducir y la renta que se desea obtener y el gasto de vacaciones de trabajadores, por ejemplo, son plenamente causales, pero a pesar de ello no podrán ser deducibles por la restricción descrita en la menciona Ley.

Asimismo se debe indicar que, el Comité de Normas Internacionales de Contabilidad (1989), a través del Marco Conceptual para la Preparación y Presentación de los Estados Financieros, señala que

Se reconoce un gasto en el estado de resultados cuando ha surgido un decremento en los beneficios económicos futuros, relacionado con un decremento en los activos o un incremento en los pasivos, y además el gasto puede medirse con fiabilidad. En definitiva, esto significa que tal reconocimiento del gasto ocurre simultáneamente al reconocimiento de incrementos en las obligaciones o decrementos en los activos (por ejemplo, la acumulación o el devengo de salarios, o bien la depreciación del equipo).
Los gastos se reconocen en el estado de resultados sobre la base de una asociación directa entre los costos incurridos y la obtención de partidas específicas de ingresos.

Este proceso, al que se denomina comúnmente correlación de gastos con ingresos, implica el reconocimiento simultáneo o combinado de unos y otros, si surgen directa y conjuntamente de las mismas transacciones $\mathrm{u}$ otros sucesos. Por ejemplo, los diversos componentes de gasto que constituyen el costo de las mercancías vendidas se reconocen al mismo tiempo que el ingreso ordinario derivado de la venta de los bienes.

No obstante, la aplicación del proceso de correlación, bajo este Marco Conceptual, no permite el reconocimiento de partidas, en el balance, que no cumplan la definición de activo o de pasivo (p. 76).

Como se ha señalado en los párrafos precedentes, para la determinación de la renta neta empresarial, se parte de un ingreso neto devengado sobre el cual se aplica el costo computable, obteniendo la renta bruta para luego aplicar los gastos necesarios para generar y mantener la fuente cumpliendo el principio de causalidad; y en razón de ello, no deberían existir gastos o costos cuya deducción en el ejercicio gravable en el que se devengaron se encuentren condicionados al pago previo, es decir, si estos gastos o costos cumplen con el principio de causalidad, y por ello son necesarios para la generación de la renta, éstos deberían ser admitidos, como costo o gasto por la Ley del Impuesto a la Renta; sobre todo porque en la Ley del Impuesto a la Renta, el legislador no ha definido que se debe entender como devengado y para hallar su significado y realizar la aplicación correcta en función a lo ahí establecido, debemos recurrir a las normas contables.

Es importante señalar lo que mencionan algunos especialistas sobre las definiciones de costos y gastos, relacionados con la generación de ingresos:

En la NIC 2, en lo referente al costo de existencias de un proveedor de servicios señala que en el caso de que un prestador de servicios tenga inventarios, los medirá por los costos que suponga su producción. Estos costos se componen fundamentalmente de mano de obra y otros costos del personal directamente involucrado en la prestación del servicio, incluyendo personal de supervisión y otros costos indirectos atribuibles. La mano de obra y los demás costos relacionados con las ventas, y con el personal de administración general, no se incluirán en el costo de los inventarios, sino que se contabilizarán como gastos del periodo en el que se hayan incurrido. Los costos de los inventarios de un prestador de servicios no incluirán márgenes de ganancia ni costos indirectos no atribuibles que, a menudo, se tienen en cuenta en los precios facturados por el prestador de servicios. (Ministerio de Economía y Finanzas, 2014).

Asimismo, Hernández (como se citó en Vásquez, 2009) señala:

Para propósitos de la contabilidad financiera, el costo se define como un desembolso que se registra en su totalidad como un activo y se convierte en gasto cuando "rinde sus beneficios" en el futuro. Por consiguiente, una cuenta de costo es una cuenta de activo. El gasto se define como un desembolso que se consume corrientemente, o como un costo que "ha rendido 
ya su beneficio". Para fines de la contabilidad administrativa, estos términos no se definen con tal rigidez, pues "a veces se utilizan para significar un activo y en otras ocasiones un gasto (p. 29).

Además, el Comité de Normas Internacionales de Contabilidad (1989), indica que la definición de gastos incluye tanto las pérdidas como los gastos que surgen en las actividades ordinarias de la empresa. Entre los gastos de la actividad ordinaria se encuentran, por ejemplo, el costo de las ventas, los salarios y la depreciación. Usualmente, los gastos toman la forma de una salida o depreciación de activos, tales como efectivo y otras partidas equivalentes al efectivo, inventarios o propiedades, planta y equipo.

Asimismo, se debe tomar en cuenta el principio del devengado, que es el principio rector de la imputación de los gastos en la Ley del Impuesto a la Renta, respecto del cual García (1967), lo define como la aceptación del método del rédito "devengado" como sistema para imputarlo al ejercicio fiscal, por oposición al de rédito "percibido", importa admitir que un rédito devengado importa sólo una disponibilidad jurídica, pero no una disponibilidad económica o efectiva del ingreso. Hay un derecho del beneficiario que se incorpora a su patrimonio, que como tal puede valuarse en moneda, hay una realización potencial (...), pero no hay una realización efectiva (...), y no podría haberla, porque no hay todavía la disponibilidad para el beneficiario.

También, tiene especial énfasis, el concepto de determinación de la renta neta; ya que, como regla general estas deducciones que aminoran las rentas brutas, deben ser siempre re- gidas por el principio de causalidad, es decir, tiene que existir una asociación entre los gastos que se deducen y la necesidad de que estén vinculados con la generación de las propias renta En el artículo $37^{\circ}$ del TUO de la LIR en el Perú, se detalla cuáles son los gastos que el legislador considera deducibles, a efectos de determinar la renta neta empresarial; para lo cual ha señalado: "A fin de establecer la renta neta de tercera categoría se deducirá de la renta bruta los gastos necesarios para producirla y mantener su fuente, así como los vinculados con la generación de ganancias de capital, en tanto la deducción no esté expresamente prohibida por esta Ley, en consecuencia son deducibles (Sunat, 2004).

Para García (1980), la causalidad se define como concepto general, puede decirse que del propio principio de causalidad surgen implícitos algunos de los caracteres que deben revestir los gastos para ser deducibles: ser necesarios (algunas legislaciones hablan de "estrictamente imprescindibles") para obtener la renta o mantener la fuente; ser normales de acuerdo al giro del negocio, mantener cierta proporción con el volumen de operaciones, etc.

Según Matteucci (2010), en su texto, El principio de causalidad y su implicancia en el sustento de los gastos en el impuesto a la renta con relación a la aplicación de este principio señala que se pueden presentar dos concepciones:

Concepción restrictiva del Principio de Causalidad, bajo esta concepción se permite la deducción de los gastos que tengan la característica de necesarios e indispensables para poder producir la renta y/o también mantener la fuente generadora, es decir, se entienden por gastos necesarios aquellos desembolsos estrictamente indispensables.

Concepción amplia del Principio de Causalidad, se permite la deducción de todos aquellos gastos necesarios para producir y/o mantener la fuente generadora de renta, tomando en cuenta adicionalmente la totalidad de desembolsos que puedan contribuir de manera indirecta a la generación de renta.

El Tribunal Fiscal en su Resolución $N^{\circ}$ 4807-1-2006, señaló que los gastos de mantenimiento se rigen por el principio general de causalidad recogido en el artículo $37^{\circ}$ de Ley del Impuesto a la Renta, según el cual el nexo causal entre gastos e ingresos no debe entenderse referido solamente a la producción de rentas, sino también, y de manera general referida al engarce que debe existir con el ejercicio de la actividad productiva a cuyo servicio se disponen recursos materiales y humanos.

Por lo expuesto en los párrafos anteriores la causalidad no debe entenderse en un sentido restrictivo, sino amplio, mediante el cual debe existir una vinculación entre el gasto y producción de renta, que debe verificarse caso por caso.

En ese sentido, la restricción de la deducción de gastos causales, afectarían el principio capacidad contributiva sobre el cual los especialistas han señalado lo siguiente:

García (como se citó en Ríos, 2002), indica que:

Estamos conscientes, por otra parte, de que la tributación no puede ser producto de una concepción eminentemente jurídica, su contenido se determina a su vez, por 
decisiones de carácter político, económico y social. Pretender en consecuencia, que el legislador apegado, únicamente a criterios de equidad, vote por tal o cual normativa tributaria, resulta incoherente con la situación nacional (p. 48-49).

Bravo (2009) precisa que:

El principio de Capacidad Contributiva parte de la premisa fundamental sustentada en que los contribuyentes deben ser tratados con igualdad y que los pagos de tributos por ellos efectuados implican un sacrificio igual para cada uno de ellos, lo que genera como consecuencia que los contribuyentes con igual capacidad económica paguen prestaciones equivalentes; y que los contribuyentes con diferente capacidad económica paguen prestaciones tributarias diversas, con ninguna utilidad o pérdida de utilidad equivalentes (p. 223).

Jarach (como se citó en Vásquez, 2009) señala:

Que la capacidad contributiva es un concepto a priori para el Derecho, lo que hace que se dude de la posibilidad de introducir en la dogmática jurídica un concepto apriorístico. Y es que es problema de la política financiera, (en base a sus presupuestos teóricos) elaborar el concepto de capacidad contributiva, con lo cual el legislador contaría con los elementos necesarios para discernir cuáles situaciones de hecho deben ser elegidos como síntoma de capacidad contributiva (p. 44).

Giulliani (1984) comenta: Responde a un encomiable propósito de justicia tributaria a ser tenido en cuenta por el legislador, según su libre apreciación pero que no puede ser erigido en condición de dogma jurídico.

Asimismo Giulliani (1984) señala que con el propósito, loable por cierto de evitar la discrecionalidad en el ejercicio del poder tributario, una parte de la doctrina pretende condicionar su legitimidad a la existencia en el sujeto pasivo, de idoneidad o capacidad económica. La racionalidad de la tributación dependerá, según aquélla, de la capacidad contributiva de las personas.

Villegas (2000) señala que:

Las constituciones incorporan también el principio de capacidad contributiva que constituye el límite material en cuanto al contenido de la norma tributaria (así como el principio de legalidad o reserva es el límite formal respecto al sistema de producción de esa norma). Ambos principios constituyen el estatuto básico del contribuyente que la constitución ampara (p. 203).

Sainz de Bujanda (1962) indica que:

El principio de capacidad contributiva actúa, sobre todo, dentro de la tributación como sistema, de tal suerte que la adecuación de los hechos imponibles a la capacidad contributiva se produce, primordialmente, a través de la conexión de unos hechos con otros y de la carga total que generan para los sujetos que lo realizan. El fundamento por el cual el legislador toma un hecho de la vida como presupuesto de una obligación tributaria es la existencia de una capacidad contributiva de la cual dicho hecho puede considerarse como índice sintomático. La ciencia tributaria al elegir un hecho imponible trata de gravar en él un objeto económico de imposición que se traduce directa o indirectamente en índice de capacidad contributiva (p. 190)

García (1999) menciona:

La capacidad contributiva, es la aptitud económica social para contribuir al sostenimiento del Estado. Si bien se la vincula con el principio del sacrificio, puede enfocársela también considerando las posibilidades de un individuo, más que su sacrificio. A la capacidad contributiva se la mide por índices (patrimonio, renta), o por indicios (gastos, salarios pagados, transacciones, etc. (p. 55)

Cañal (1996) señala que la capacidad contributiva es el límite absoluto y objetivo, de la capacidad contributiva, se refiere al hecho imponible, que ha de ser índice revelador de riqueza. Esta riqueza debe ser efectiva, real; por lo que el principio de capacidad contributiva, excluye la posibilidad de que se grave una renta presunta o ficticia.

Respecto a lo señalado a lo largo del presente trabajo de investigación, podemos afirmar, que el hecho de condicionar al pago previo los gastos y o costos mencionados en los artículos 1) y v) de la Ley del Impuesto a la Renta, representan una condición que se contrapone al Principio Contable del Devengado que es la hipótesis fundamental establecida en el Marco Conceptual para la preparación de los Estados Financieros y en la que se señala como se debe realizar el registro contable de los ingresos y gastos, sino que también se contraponen al Principio de Causalidad cuando se verifica que existe una asociación directa en- 
Tabla 1.

Estado de Ganancias y Perdidas

Fuente: Elaboración Propia

* Se deben adicionar a la utilidad del ejercicio el importe de las vacaciones no pagadas antes del vencimiento de la presentación de la Declaración Jurada Anual. (VALORES, 2016)

\begin{tabular}{|c|c|c|}
\hline \multicolumn{3}{|c|}{$\begin{array}{l}\text { EMPRESA S.A.C } \\
\text { Estado de Ganancias y Pérdidas - (en miles de Soles) }\end{array}$} \\
\hline Cuenta & 2015 & $2015^{*}$ \\
\hline $\begin{array}{l}\text { Ventas Netas (ingresos } \\
\text { operacionales) }\end{array}$ & 16886 & 16886 \\
\hline Costo de Ventas & -11675 & -11675 \\
\hline Utilidad Bruta & 5211 & 5211 \\
\hline \multicolumn{3}{|l|}{ Gastos de Ventas } \\
\hline $\begin{array}{l}\text { Gastos de Administra- } \\
\text { ción }\end{array}$ & $-1,948$ & -1948 \\
\hline Otros Ingresos & 5808 & 5808 \\
\hline Otros Gastos & -260 & -260 \\
\hline Utilidad Operativa & 8811 & 8811 \\
\hline Ingresos Financieros & 27 & 27 \\
\hline Gastos Financieros & -5059 & $-5,059$ \\
\hline $\begin{array}{l}\text { Resultado antes de Parti- } \\
\text { cipaciones y del Impuesto } \\
\text { a la Renta }\end{array}$ & 3779 & 3779 \\
\hline GASTOS NO ACEPTADO & JTARIAMENTE & $950(1)$ \\
\hline $\begin{array}{l}\text { Resultado antes de Parti- } \\
\text { cipaciones y del Impuesto } \\
\text { a la Renta }\end{array}$ & 3779 & 4729 \\
\hline $\begin{array}{l}\text { Participación de los tra- } \\
\text { bajadores }\end{array}$ & -300 & -378 \\
\hline Impuesto a la Renta & -856 & -1419 \\
\hline $\begin{array}{l}\text { Utilidad (Perdida) Neta } \\
\text { del Ejercicio }\end{array}$ & 2623 & 2932 \\
\hline
\end{tabular}

tre el gasto incurrido y el ingreso generado y tampoco se cumpliría con el principio de capacidad contributiva.

\section{MATERIAL Y MÉTODOS}

La presente investigación es de tipo transicional al estar constituida por tres variables, donde la primera está condicionada por la segunda, y está a su vez, condicionada por la tercera investigación.
Se utilizaron una serie de métodos como las generales que abarcan al Histórico, ya que permite conocer los diversos tratamientos tributarios que han regido nuestro ordenamiento tributario en el Impuesto a la Renta con respecto a las deducciones de los gastos necesarios sujetos al pago, para determinar las rentas netas empresariales.

Comparativo, a través de este método se analizó y comparó con algunas le- gislaciones tributarias de otros países, que abordan el tema del impuesto a la renta, en lo referente a la aplicación del principio del devengado en el reconocimiento de los gastos deducibles sujetos al pago, para la determinación de la renta neta empresarial.

Explicativos, porque mediante la aplicación de este método se relacionaron tres variables, para explicar los factores (medidas antielusivas) que dieron origen al condicionamiento al pago previo, para tener derecho a la deducción de los gastos causales que se encuentran descritos en los incisos l) y v) del artículo $37^{\circ}$ de la Ley del Impuesto a la Renta.

Por otro lado, se uso métodos específicos como de Analogía permitiendo conocer las semejanzas o diferencias con otros tipos de restricciones también sujetas al pago, a los gastos deducibles para la determinación de las rentas netas empresariales.

Métodos Inferenciales el de la Inducción-deducción, la primera me permitió evaluar y estudiar las diversas deducciones que existen en la legislación nacional para la determinación de las rentas netas empresariales y la segunda me ayudó a analizar la mejor forma de aplicar el principio del devengado evitando incorporar restricciones indebidas a los gastos que vayan en contra del referido principio.

Mediante el método Deductivo por su Naturaleza se analizaron las normas tributarias vigentes, utilizadas para la determinación de las rentas netas empresariales, adicionalmente revisé la legislación comparada y la jurisprudencia aplicable, con la finalidad de proponer una regulación en la imputación de los gastos deducibles restringidos al pago previo, que respete los principios del devengado y 
causalidad en la determinación de las rentas netas empresariales; así como plantear medidas que fortalezcan las labores de control tributario.

Y el método Descriptivo que es un método que consiste en analizar e interpretar sistemáticamente un conjunto de hechos, a través del cual se identifica y conoce la naturaleza de una situación, ya que no está dirigida a la verificación de la hipótesis.

Asimismo, en la presente investigación se utilizó como instrumento de recolección de datos de campo la encuesta, utilizando preguntas de escala nominal (sexo, profesión, etc.), y de escala de intervalos (Totalmente de Acuerdo, Parcialmente de Acuerdo, Indiferente, Parcialmente en Desacuerdo, Totalmente en desacuerdo); a fin de recoger la información de los profesionales expertos, respecto del efecto tributario que origina la indebida restricción de deducir costos $\mathrm{y}$ gastos condicionándolos al pago $\mathrm{y}$ que cumplen con el principio del devengado y de causalidad.

Para ello se elaboró un cuestionario de preguntas en la que se encuestó a profesionales de las carreras de Contabilidad, Derecho y Economía, especializados en el tema tributario.

Del mismo modo, se utilizaron Técnicas para la obtención de información documental, para lo cual se utilizaron las fichas bibliográficas con el fin de analizar el material doctrinario, normas tributarias y contable.

\section{RESULTADOS}

Luego de la evaluación de las encuestas, de la recolección de la información se presenta un caso en el que se mostrará la incidencia que tiene la restricción de la deducción de algunos gastos en la determinación del
Impuesto a la Renta corriente:

Se asume que la empresa ha contabilizado por concepto de remuneraciones vacacionales, durante el ejercicio gravable 2015 la suma de S/ 950 miles de soles, que permanecen pendientes de pago a julio 2016 (fecha posterior a la presentación de la Declaración Jurada Anual del Impuesto a la Renta correspondiente al ejercicio gravable 2015).

Como se puede apreciar en el Estado de Ganancias y Pérdidas, que se muestra en la Tabla 1, si tributariamente se aceptara que la empresa deduzca el importe de las vacaciones cargadas al gasto su utilidad se mantendría en 3779 miles de soles; sin embargo, como las vacaciones se encuentra pendientes de pago, este concepto no constituye un gasto deducible para el ejercicio gravable 2015, a pesar que ha devengado en el mencionado ejercicio, por lo tanto, el importe correspondiente al gasto por concepto de vacaciones debe ser adicionado a la utilidad inicialmente determinada, generando un incremento en la utilidad del ejercicio y por ende un mayor pago del impuesto a la renta, de 856 miles de soles a 1419 miles de soles.

Del Estado Financiero mostrado en la Tabla 1, se observa que la restricción de la deducibilidad del gasto de vacaciones, ocasiona un mayor pago de impuesto a la renta corriente y por tanto, una menor utilidad.

\section{DISCUSIÓN}

La indebida restricción en la imputación de gastos o costos, condicionándolo al pago previo, se contrapone a los principios del devengado y causalidad.

La Ley del Impuesto a la Renta establece una indebida restricción en la deducción de los gastos o costos, que son necesarios para la generación de la renta neta empresarial, condicionándolos al pago previo de los mismos, generando ello una mayor renta neta empresarial, lo que trae como consecuencia el mayor pago de impuestos.

La Ley del Impuesto a la Renta procede adecuadamente cuando señala que para efectos de poder deducir los gastos, estos deberán adicionalmente de cumplir con el principio del devengado y causalidad, con los criterios de razonabilidad en relación con los ingresos y generalidad para algunos tipos de gastos, porque siempre se debe cumplir con la correlación de ingresos y gastos.

La Ley del Impuesto a la Renta debe mantenerse contemplando los principios de Causalidad y Devengado para la determinación correcta de la Renta Neta Empresarial y se deberían buscar otros mecanismos para que los contribuyentes de todas las rentas tributen lo que en estricto les corresponde.

\section{REFERENCIAS BIBLIOGRÁFICAS}

Bravo, J. (2009). Breves reflexiones sobre el desarrollo jurisprudencial del principio de capacidad contributiva. UIS et Veritas - PUCP. (38), pp. 222227

Cañal, F. (1996). Revisión crítica del principio de capacidad contributiva y de sus distintas formulaciones doctrinales. Revista de la Universidad Autónoma de San Luis. Potosí, México, (4), pp. 50 - ss

Comité de Normas Internacionales de Contabilidad. (1989). Marco Conceptual para la Preparación y Presentación de los Estados Financieros. Recuperado de https://www.bps.gub.uy/ bps/file/10014/2/marco-conceptual- 
para-la-preparacion-y-presentacionde-los-estados-financieros.pdf

García, C. (1999). Derecho Tributario. Buenos Aires: Editorial DEPALMA

García, H. (1967). El Concepto de rédito en la doctrina y en el derecho tributario. Buenos Aires: Ediciones DEPALMA.

Garcia, R. (1980). Teoría y Técnica sobre el Impuesto a la Renta. Santo Domingo: Instituto de Capacitación de Republica Dominicana.

Giuliani, C. (1984). Derecho Financiero. Buenos Aires, Argentina: Editorial DEPALMA.

Matteucci, J. (05 de enero de 2010). El principio de causalidad y su implicancia en el sustento de los gastos en el impuesto a la renta (Mensaje en un blog). Recuperado de http://blog.pucp.edu.pe/ blog/blogdemarioalva/2010/01/05/ el-principio-de-causalidad-y-su-implicancia-en-el-sustento-de-los-gastos-en-el-impuesto-a-la-renta/

Ministerio de Economía y Finanzas (2014). Normas internacionales de contabilidad oficializadas - NIC. Recuperado de https://www.mef.gob.pe/ es/consejo-normativo-de-contabili$\mathrm{dad} / \mathrm{nics}$

Rios, G. (2002). Conceptos de la Reforma Fiscal. México, D.F., México: Instituto de Investigaciones Jurídicas.

Sunat. (2000). Oficio $N^{o}$ 015-2000 K0000. Recuperado de http://www.sunat.gob.pe/legislacion/oficios/2000/ oficios/o0152000.htm
Sunat. (2004). Ley de Impuesto a la Renta. Recuperado de http://www. sunat.gob.pe/legislacion/renta/ley/ fdetalle.htm

Sainz de Bujanda, F. (1962). Hacienda y Derecho. Madrid: Instituto de Derechos Públicos.

Villegas, H. (2000). Manual de Finanzas Públicas. Buenos Aires Editorial DEPALMA.

Vasquez, C. (2009). Los Gastos deducibles y el principio de causalidad en la determinación de las rentas netas empresariales-caso peruano. (Tesis de Maestría). Universidad Nacional Mayor de San Marcos, Lima, Perú 